\title{
Diagnosis and Management of Choledochal Cysts
}

\author{
Chiranjiva Khandelwal • Utpal Anand • Bindey kumar • \\ Rajeev N. Priyadarshi
}

Received: 30 November 2011 / Accepted: 30 November 2011 / Published online: 10 December 2011

(C) Association of Surgeons of India 2011

\begin{abstract}
Choledochal cysts are rare disease and of unknown etiology. They are typically a surgical problem of infancy and childhood, but in nearly $20 \%$ of the patients the diagnosis is delayed until adulthood. The presentation and therapeutic strategies for choledochal cysts in adult may differ from that of childhood. The surgical management of choledochal cysts in adults is complicated by associated hepatobiliary pathology. Despite the absence of clinical trials, a consensus for the management of choledochal cysts is excision. This review examines the spectrum of hepatobiliary pathology encountered with choledochal cysts and the surgical alternatives for managing choledochal cysts based on review of relevant literature in the English language indexed on MEDLINE.
\end{abstract}

C. Khandelwal

Bihar Institute of Gastroenterology,

Patna, India

U. Anand $(\bowtie)$

Department of GI Surgery,

Indira Gandhi Institute of Medical Sciences,

Sheikhpura,

Patna, Bihar, India

e-mail: utpalanand2@gmail.com

B. kumar

Department of Paediatric Surgery,

Indira Gandhi Institute of Medical Sciences,

Sheikhpura,

Patna, Bihar, India

R. N. Priyadarshi

Department of Radiodiagnosis,

Indira Gandhi Institute of Medical Sciences,

Sheikhpura,

Patna, Bihar, India
Keywords Choledochal cyst · Hepaticojejunostomy · Cholangiocarcinoma $\cdot$ Pancreatitis

\section{Introduction}

Choledochal cysts are congenital anomalies of the bile ducts and are defined as abnormal, disproportionate, cystic dilatation of the biliary duct. The incidence of bile duct cysts ranges from 1 in 13,000 to 1 in 2 million births [1]. More than $60 \%$ of them present during the first year of life. A proportion of them present in adulthood, and their presentations differ compared to childhood cases [2]. There is a higher incidence in females [3, 4]. The presentation is often vague and nonspecific. However, the diagnosis is facilitated by modern imaging techniques. Some aspects of optimal management are still controversial. This is a review of choledochal cysts based on available literature.

\section{Classification}

Alonso-Lej et al published the first systematic description of choledochal cysts, based on the clinical and anatomic findings in 96 cases in 1959 [5]. They classified choledochal cysts into three types and described the therapeutic strategies for each type. This classification was further refined by Todani and colleagues who included five major types and several subtypes [6]. Type I cysts are a dilatation of the extrahepatic bile duct. They are the most common type and seen in $75-85 \%$ of cases $[7,8]$. Type I cysts may be further classified as cystic (IA), focal (IB) or fusiform (IC). The type II cyst is diverticulum of the common bile duct. Type III is represented by a cystic dilatation of the intramural portion of the common bile duct known as 
choledochoceles. Type IVA lesions involve both the intra and extrahepatic portions of the bile ducts, and type IVB are multiple cysts limited to the extrahepatic bile ducts. Type IVA cysts are the second most common type after type I. Type V is synonymous with Caroli disease and describes the abnormalities of the intrahepatic bile ducts, resulting in multiple segmental intrahepatic cystic biliary dilatations.

\section{Histopathology}

Histopathologically, the type I, II, and IV choledochal cysts are similar and consist of a wall of dense collagenous tissue with smooth muscle bundles. A mucosal lining may be entirely absent or may present in a patchy distribution. Some degree of inflammatory reaction is usually present. Type III cysts are usually lined with duodenal type mucosa, but may be covered with a mucosa similar to that of the bile duct.

\section{Etiology}

Choledochal cysts are believed to be congenital in origin; however, exact etiology remains unknown. Multiple etiologic theories have been proposed for the origin of choledochal cysts. The most widely accepted theory is that cystic dilatation of bile ducts is related to an anomalous pancreaticobiliary ductal union (APBDU) [9]. An APBDU is defined as abnormal union of the pancreatic duct, and the common bile duct is located far from the duodenum, leading to a long common channel. Therefore, the action of the sphincter of Oddi is affected, and pancreaticobiliary reflux occurs, resulting in various pathological conditions in the biliary tract and the pancreas such as inflammation, ectasia, and ultimately dilatation. In experimental canine studies, anastomosis of the common bile duct to the pancreatic duct resulted in progressive dilatation of the common bile duct supports this theory [10]. However, the possibility of anastomotic stricture, following such challenging surgery may result in the dilatation rather than pancreatic juice reflux, cannot be ruled out. Anomalous pancreaticobiliary union is detected in $57-96 \%$ of cases of choledochal cysts, and therefore cannot account for the minority of cases with normal ductal entry into the ampulla of Vater [11-13].

Obstruction of the common bile duct is another etiological theory for choledochal cysts and is also supported by other animal models. In neonatal animal models, ligation of the common bile duct causes a dilatation, morphologically resembling a type I choledochal cyst, whereas in adults, generalized dilatation of the whole biliary system can be seen [14].

Recently, abnormal function and spasm of the sphincter of Oddi has been associated with choledochal cysts $[15,16]$.
The abnormal function of the sphincter of Oddi may result in a functional obstruction to the common bile duct, thus predisposing to choledochal cysts. This functional obstruction at the sphincter of Oddi also predisposes to pancreatic juice reflux into the biliary tree.

Kusunoki et al showed abnormally a few ganglion cells in the narrow portion of the common bile duct in patients with a choledochal cyst would result in a functional obstruction and proximal dilatation in the same manner as achalasia of the esophagus or Hirschprung disease [17].

There are a few reports of familial cases of choledochal cysts and associated anomalies [18].

It could be concluded on the basis of evidences that some anatomical or functional obstruction in distal common bile duct and raised intraductal biliary pressure are the most likely causes of choledochal cysts.

Type IVA cysts are more common in adults than in children, raising the possibility that although the lesions may be congenital, they may progress with time [19].

\section{Presentation}

The classical triad of jaundice, right upper quadrant mass, and abdominal pain is present in only a minority of patients $(0-17 \%)$ [20-22]. It is more commonly seen in children than in adults, and $85 \%$ of children have at least two features of the triad at presentation, compared with only $25 \%$ of adults [23]. Other presenting features of choledochal cysts are cholangitis, pancreatitis, and biliary peritonitis from cyst rupture [21, 24-26].

\section{Investigation}

Ultrasound (US) is the best initial method for evaluating the entire intrahepatic and extrahepatic biliary system and gall bladder. US shows a choledochal cyst as a characteristic cystic or fusiform dilatation of common hepatic duct or the intrahepatic ducts or sometimes a cyst in the porta hepatis, separate from the gallbladder. It can also demonstrate the associated complication such as cystolithiasis, cholangitis, and malignancy. US is less accurate for the specific diagnosis of bile duct cysts in adults who have more secondary malignant and benign causes for bile duct dilatation. Computed tomography (CT) is infrequently required in the situation where the distal common bile duct is not visualized due to bowel gas. Ultrasound and CT are excellent modalities for detecting cystic right upper abdominal lesions and for assessing their size and extent, but the biliary origin of the cyst may not be always reliably commented. The presence of intrahepatic ductal dilatation provides the important clue. The gastrointestinal duplication cysts, omental cysts, 
mesenteric cysts, hepatic cysts, and pancreatic pseudocysts are other main radiological differential diagnosis of a large cystic lesion at the porta hepatis.

Magnetic resonance cholangiopancreatography (MRCP) and endoscopic retrograde cholangiopancreatography (ERCP) are the diagnostic methods of choice for biliary ductal pathology $[1,27]$. MRCP is emerging as a highly sensitive, safe, and noninvasive diagnostic preoperative technique for the detection of choledochal cysts. MRCP is rapidly replacing diagnostic ERCP in various pancreaticobiliary diseases. MRCP may also supersede the diagnostic role of ERCP in patients with choledochal cysts. However, MRCP shows limited capacity to detect associated ductal anomalies or small choledochocele [28]. MRCP is not useful in pediatric patients who are not able to hold breath for a few seconds, a requisite for breath-hold MRCP sequences. In clinical practice, MRCP is recommended before ERCP in patients suspected of having choledochal cysts on US.

\section{Associated Hepatobiliary Pathology}

Cystolithiasis

Cystolithiasis is the most common accompanying condition in adults with choledochal cysts. The prevalence of intracystic stones ranges from 2 to $72 \%$ in adults [29]. Most intracystic stones have been described as soft, earthy, and pigmented in appearance, supporting the bile stasis as a primary etiologic factor.

Hepaticolithiasis has been recognized with increasing frequency with long-term follow-up and may occur with or without evidence of anastomotic stricture [30]. Usually hepaticolithiasis occurs in type IVA choledochal cysts. A study has shown that more than $80 \%$ of type IVA choledochal cysts are associated with a membranous or septal stenosis of the major lobar bile ducts near the confluence favoring hepaticolithiasis [31].

\section{Pancreatitis}

This is a common presentation of choledochal cysts particularly in adults. This may be due to the activation of pancreatic enzymes by bile reflux, in association with an anomalous pancreaticobiliary union and the presence of cystolithiasis and cholelithiasis [32].

\section{Cholangitis}

As with pancreatitis, cholangitis is a common complication of choledochal cysts and may be the presenting feature as mentioned earlier. It is also a commonly reported complication after surgical management.
Portal Hypertension

Portal hypertension associated with choledochal cysts may be due to secondary biliary cirrhosis or fibrosis, portal vein thrombosis, or Caroli disease with congenital hepatic fibrosis [33]. This has been reported to be the presenting feature in $10 \%$ of children in one series [21].

\section{Malignancy}

Malignancies of the hepatobiliary tract arising in or associated with choledochal cysts are cholangiocarcinoma or adenocarcinoma, adenoacanthoma, squamous cell carcinoma, anaplastic carcinoma, bile duct sarcoma, hepatoma, pancreatic carcinoma, and gallbladder carcinoma.

Malignancies associated with choledochal cysts may arise within the cyst or elsewhere within the liver or pancreaticobiliary tract. Malignancies may be associated with any type of bile cysts although prevalence of cancer is significantly greater in type I and IV cysts. The etiology of cyst-associated malignancies is unknown. Bile stagnation and the development of intrabiliary carcinogens leading to epithelial malignant degeneration are postulated as the most common mechanism.

The prognosis for patients with cholangiocarcinoma arising in choledochal cysts is as grim as for cholangiocarcinoma in general, with median survival reported in the range of 6-21 months [2, 34, 35]. Malignant change in association with choledochal cysts has been reported in pediatric cases, and it should therefore be suspected in any choledochal cyst appearing after infancy [36].

The incidence of gallbladder carcinoma in patients with ductal malunion without choledochal cyst (forme fruste choledochal cyst) was $50 \%$ in one study, and only $5 \%$ in patients with malunion and choledochal cysts [37]. In the patients without cysts, all the biliary malignancies were in the gallbladder, whereas in the patients with cysts, in addition to the $5 \%$ with gallbladder cancer, $14 \%$ had cholangiocarcinoma arising in the cyst.

It has been demonstrated that the histological changes in choledochal cysts progress with patient age at presentation, through epithelial denudement to inflammatory infiltrates, glandular metaplasia, and ultimately malignancy [38].

\section{Management}

\section{General Principles}

The surgical management of choledochal cysts is based on the cyst type and associated hepatobiliary pathology. In general, all bile duct cysts should be excised and bile flow re-established by mucosa-to-mucosa biliary-enteric 
anastomosis. External drainage alone has no definitive role in the surgical management of choledochal cysts. Long-term follow-up must be maintained in adults because of the agerelated risk of malignancy and the frequency of late anastomotic strictures in patients treated without cyst resection.

\section{Type I Cyst}

The treatment of choice of type I bile duct cysts in adults is total cystectomy and Roux-en-Y hepaticojejunostomy. The advantages of this procedure include a reduced incidence of anastomotic strictures, stones formation, cholangitis, and intracystic malignancy.

The clinical results of total cystectomy and Roux-en-Y hepaticojejunostomy have been excellent. Morbidity and mortality have not been greater than that of drainage by Roux-en-Y choledochocystojejunostomy [35]. Recurrent cholangitis due to anastomotic strictures has been reported in $10-25 \%$ of patients [29]. Although reduction of malignancy by cyst excision has been suggested by some series, cancer has developed after cyst excision.

Technically, cyst excision in adults can be done by initially mobilizing gallbladder from liver bed to dissect the cyst away from hilar structures. Identification of portal vein and isolation and control of hepatic artery should be done before dissection of the posterior wall of the cyst especially if hypervascularity and dense adhesions are encountered. Before division of the cyst, the distal cyst is dissected from the pancreas to identify the pancreaticobiliary ductal junction. The cyst is transected distally within the head of pancreas, and the distal bile duct is ligated carefully just proximal to its junction with the pancreatic duct. Biliaryenteric flow is re-established through a wide mucosa-tomucosa Roux-en-Y hepaticojejunostomy at the level of the hilum.

Laparoscopic treatment of type I choledochal cyst has been reported and it warrants further evaluation [39, 40].

Portal hypertension due to secondary biliary cirrhosis and inflammatory adhesions from severe pancreatitis or past drainage procedures rarely precludes cyst excision. Rouxen-Y choledochocystojejunostomy is the preferred alternative treatment in such circumstances. Portal decompression by central splenorenal shunt followed by drainage surgery after 6-12 weeks is sometimes required. In older patients with repeated cholangitis and marked pericystic inflammation, this disease may be best managed with resection of the anterolateral part of the cyst followed by an endocystic resection of the lining, leaving the back wall adjacent to the portal vein in place, as reported by Lilly [41].

If patients have previously been treated by a cyst enterotomy internal drainage procedure, $70 \%$ of them require reoperation for the occurrence of complications, including cholangitis and hepatolithiasis [29]. Indeed it has been recommended that patients who have previously undergone internal drainage procedures should undergo reoperation with cyst excision (even if asymptomatic) as prophylaxis against complications in particular cases of malignant cysts, even though the complications of surgery for excision after previous internal drainage procedure are more frequent than those seen after primary cyst excision $[42,43]$.

\section{Type II Cyst}

Treatment of type II cysts arising as a lateral diverticulum of the common bile duct is surgical excision. Depending on the size of the neck of the cyst at the junction with the common bile duct, the neck may be closed primarily or with T-tube decompression of the common bile duct. However, when these cysts arise from the intrapancreatic portion of the common bile duct, drainage into the duodenum is technically easier. A few patients have this type of choledochal cyst, so no large experience has been reported.

\section{Type III Cyst}

Choledochoceles are the true cyst of the distal common bile duct protruding into duodenum. Patients present with biliary colic, cholangitis, or pancreatitis. Until recently transduodenal cyst excision with or without sphincterotomy was the treatment of choice [44]. Because the common bile duct and major pancreatic duct open into the cyst, careful attention is necessary to protect these ducts and reanastomose them to the duodenal mucosa. Now, endoscopic sphincterotomy and cyst unroofing have become the treatment of choice [4548]. Although transduodenal excision eliminates the risk of malignancy, the fact that only three cases of carcinoma are reported in choledochoceles, the risk of cancer alone unjustifies the treatment by surgery [44].

\section{Type IV Cyst}

The extrahepatic component of type IVA and IVB cysts is approached as a type I choledochal cyst. Transduodenal sphincteroplasty and Roux-en-Y hepaticojejunostomy complete the treatment of type IVB choledochal cysts, which have choledochocele component. The extent of the resection in type IVA cysts is controversial. Several authors advocate management by excision of the extrahepatic component only, with hepaticoenterostomy [49, 50]. However, malignancy has been reported to arise in the intrahepatic cysts as described above, and it has also been reported to occur after resection of the extrahepatic cyst with hepaticojejunostomy [51]. Clearly, when the intrahepatic cysts are widespread, they cannot be excised; however, when the intrahepatic disease is localized, it would seem reasonable to perform 
the relevant partial hepatectomy. For the same reason, partial hepatectomy has been practiced for Caroli disease.

There is a report of cylindrical intrahepatic ductal dilatation in type IVA disease, regressing spontaneously after common duct excision and hepaticojejunostomy, compared with cystic intrahepatic disease, which does not regress [52]. However, it seems likely that the cylindrical intrahepatic disease represents a type I cyst with an element of obstruction causing proximal dilatation, rather than a true type I.

\section{Conflict of Interest Nil.}

\section{Funding Sources Nil.}

\section{References}

1. Söreide K, Körner H, Havnen J, Söreide JA (2004) Bile duct cysts in adults. Br J Surg 91(12):1538-1548

2. Liu CL, Fan ST, Lo CM, Lam CM, Poon RT, Wong J (2002) Choledochal cysts in adults. Arch Surg 137(4):465-468

3. Watanatittan S, Niramis R (1998) Choledochal cyst: review of 74 pediatric cases. J Med Assoc Thai 81(8):586-595

4. Chen HM, Jan YY, Chen MF et al (1996) Surgical treatment of choledochal cyst in adults: results andlong-term follow-up. Hepatogastroenterology 43(12):1492-1499

5. Alonso-Lej F, Rever WB Jr, Pessagno DJ (1959) Congenital choledochal cysts, with a report of 2, and an analysis of 94 cases. Surg Gynecol Obstet 108:1-30

6. Todani T, Watanabe Y, Narusue M, Tabuchi K, Okajima K (1977) Congenital bile duct cysts: classification, operative procedures, and review of thirty-seven cases including cancer arising from choledochal cyst. Am J Surg 134(2):263-269

7. Flanigan DP (1975) Biliary cysts. Ann Surg 182(5):635-643

8. Yamaguchi M (1980) Congenital choledochal cyst. Analysis of 1,433 patients in the Japanese literature. Am J Surg 140(5):653-657

9. Babbitt DP (1969) Congenital choledochal cysts: new etiological concepts on anomalous relationships of the common bile duct and pancreatic bulb. Ann Radiol (Paris) 12(3):231-240

10. Ohkawa H, Sawaguchi S, Yamazaki Y, Ishikawa A, Kikuchi M (1982) Experimental analysis of the ill effect of anomalous pancreaticobilliary ductal union. J Pediatr Surg 17(1):7-13

11. Swisher SG, Cates JA, Hunt KK et al (1994) Pancreatitis associated with adult choledochal cysts. Pancreas 9(5):633-637

12. Stringer MD, Dhawan A, Davenport M, Mieli-Vergani G, Mowat AP, Howard ER (1995) Choledochal cysts: lessons from a 20-year experience. Arch Dis Child 73(6):528-531

13. Song HK, Kim MH, Myung SJ et al (1999) Choledochal cyst associated with anomalous union of pancreaticobiliary duct (AUPBD) has a more grave clinical course than choledochal cyst alone. Korean J Intern Med 14(2):1-8

14. Spitz L (1977) Experimental production of cystic dilatation of the common bile duct in lambs. J Pediatr Surg 12(1):39-42

15. Imazu M, Iwai N, Tokiwa $\mathrm{K}$, Shimotake $\mathrm{T}$, Kimura $\mathrm{O}$, Ono $\mathrm{S}$ (2001) Factors of biliary carcinogenesis in choledochal cysts. Eur J Pediatr Surg 11(1):24-27

16. Schweizer P, Schweizer M (1993) Pancreaticobiliary long common channel syndrome and congenital anomalous dilatation of the choledochal duct: study of 46 patients. Eur J Pediatr Surg 3 (1):15-21
17. Kusunoki M, Saitoh N, Yamamura T, Fujita S, Takahashi T, Utsunomiya J (1988) Choledochal cysts: oligoganglionosis in the narrow portion of the choledochus. Arch Surg 123(8):984-986

18. Iwata F, Uchida A, Miyaki T et al (1998) Familial occurrence of congenital bile duct cysts. J Gastroenterol Hepatol 13(3):316-319

19. Todani T, Narusue M, Watanabe Y, Tabuchi K, Okajima K (1978) Management of congenital choledochal cyst with intrahepatic involvement. Ann Surg 187(3):272-280

20. Sherman P, Kolster E, Davies C, Stringer D, Weber J (1986) Choledochal cysts: heterogeneity of clinical presentation. J Pediatr Gastroenterol Nutr 5(6):867-872

21. Samuel M, Spitz L (1996) Choledochal cyst: varied clinical presentations and long-term results of surgery. Eur J Pediatr Surg 6 (2):78-81

22. Rattan KN, Khurana P, Budhiraja S, Malik V, Pandit SK (2000) Choledochal cyst: a 10-year experience. Indian J Pediatr 67 (9):657-659

23. Lipsett PA, Pitt HA, Colombani PM, Boitnott JK, Cameron JL (1994) Choledochal cyst disease: a changing pattern of presentation. Ann Surg 220(5):644-652

24. Seema SA, Seth A, Taluja V, Bagga D, Aneja S (2000) Spontaneous rupture of choledochal cyst. Indian J Pediatr 67(2):155-156

25. Lin SL, Shan KM, Hung YB, Ng SH, Lin CY (2000) Choledochal cyst associated with acute acalculous cholecystitis. J Pediatr Gastroenterol Nutr 31(3):307-308

26. Ando K, Miyano T, Kohno S, Takamizawa S, Lane G (1998) Spontaneous perforation of choledochal cyst: a study of 13 cases. Eur J Pediatr Surg 8(1):23-25

27. Metcalfe MS, Wemyss-Holden SA, Maddern GJ (2003) Management dilemmas with choledochal cysts. Arch Surg 138(3):333-339

28. Park DH, Kim MH, Lee SK et al (2005) Can MRCP replace the diagnostic role of ERCP for patients with choledochal cysts? Gastrointest Endosc 62(3):360-366

29. Chijiiwa K, Koga A (1993) Surgical management and long-term follow-up of patients with choledochal cysts. Am J Surg 165 (2):238-242

30. Uno K, Tsuchida Y, Kawarasaki H, Ohmiya H, Honna T (1996) Development of intrahepatic cholelithiasis long after primary excision of choledochal cysts. J Am Coll Surg 183(6):583-588

31. Ando H, Ito T, Kaneko K, Seo T, Ito F (1996) Intrahepatic bile duct stenosis causing intrahepatic calculi formation following excision of a choledochal cyst. J Am Coll Surg 183(1):56-60

32. Nakamura T, Okada A, Higaki J, Tojo H, Okamoto M (1996) Pancreaticobiliary maljunction-associated pancreatitis: an experimental study on the activation of pancreatic phospholipase A2. World J Surg 20(5):543-550

33. Martin LW, Rowe GA (1979) Portal hypertension secondary to choledochal cyst. Ann Surg 190:638-639

34. Jan YY, Chen HM, Chen MF (2000) Malignancy in choledochal cysts. Hepatogastroenterology 47(32):337-340

35. Stain SC, Guthrie CR, Yellin AE, Donovan AJ (1995) Choledochal cyst in the adult. Ann Surg 222(2):128-133

36. Iwai N, Deguchi E, Yanagihara J et al (1990) Cancer arising in a choledochal cyst in a 12-year-old girl. J Pediatr Surg 25(12):12611263

37. Chijiiwa K, Kimura H, Tanaka M (1995) Malignant potential of the gallbladder in patients with anomalous pancreaticobiliary ductal junction: the difference in risk between patients with and without choledochal cyst. Int Surg 80(1):61-64

38. Komi N, Tamura T, Tsuge S, Miyoshi Y, Udaka H, Takehara H (1986) Relation of patient age to premalignant alterations in choledochal cyst epithelium: histochemical and immunohistochemical studies. J Pediatr Surg 21(5):430-433

39. Shimura H, Tanaka M, Shimizu S, Mizumoto K (1998) Laparoscopic treatment of congenital choledochal cyst. Surg Endosc 12 (10):1268-1271 
40. Tanaka M, Shimizu S, Mizumoto K et al (2001) Laparoscopically assisted resection of choledochal cyst and Roux-en-Y reconstruction. Surg Endosc 15(6):545-552

41. Lilly JR (1978) Total excision of choledochal cyst. Surg Gynecol Obstet 146(2):254-256

42. Chaudhary A, Dhar P, Sachdev A (1997) Reoperative surgery for choledochal cysts. Br J Surg 84(6):781-784

43. Kaneko K, Ando H, Watanabe Y et al (1999) Secondary excision of choledochal cysts after previous cyst-enterostomies. Hepatogastroenterology 46(29):2772-2775

44. Lopez RR, Pinson CW, Campbell JR, Harrison M, Katon RM (1991) Variation in management based on type of choledochal cyst. Am J Surg 161(5):612-615

45. Elton E, Hanson BL, Biber BP, Howell DA (1998) Dilated common channel syndrome: endoscopic diagnosis, treatment, and relationship to choledochocele formation. Gastrointest Endosc 47(6):471-478

46. Adamek HE, Schilling D, Weitz M, Riemann JF (2000) Choledochocele imaged with magnetic resonance cholangiography. Am J Gastroenterol 95(4):1082-1083
47. Siegel EG, Folsch UR (1999) Primary sclerosing cholangitis mimicking choledocal cyst type 1 in a young patient. Endoscopy 31 (2):200-203

48. Samavedy R, Sherman S, Lehman GA (1999) Endoscopic therapy in anomalous pancreatobiliary duct junction. Gastrointest Endosc 50(5):623-627

49. Hewitt PM, Krige JE, Bornman PC, Terblanche J (1995) Choledochal cysts in adults. Br J Surg 82(3):382-385

50. Belli G, Rotondano G, D’Agostino A, Iannelli A, Marano I, Santangelo ML (1998) Cystic dilation of extrahepatic bile ducts in adulthood: diagnosis, surgical treatment and long-term results. HPB Surg 10(6):379-384, discussion 384-385

51. Kobayashi S, Asano T, Yamasaki M, Kenmochi T, Nakagohri T, Ochiai T (1999) Risk of bile duct carcinogenesis after excision of extrahepatic bile ducts in pancreaticobiliary maljunction. Surgery 126(5):939-944

52. Thambi Dorai CR, Visvanathan R, McAll GL (1991) Type IVa choledochal cysts: surgical management and literature review. Aust N Z J Surg 61(7):505-510 